\title{
Process based transformation: a processual approach to implementation
}

\author{
Javed Iqbal \\ Iqra University, Islamabad
}

\begin{abstract}
The paper describes application of Pettigrew et al.'s [7] strategic change model for a radical change initiative in a large British organization. The model assumes that management can assess changing economic, business and political conditions and implement new strategies in order to improve the firm's competitive performance. The change initiative has been divided into the context, contents and process. The context provides the basis on which content can be designed and the process is reserved for implementation of envisioned changes. Given that it has been identified that the context was main trigger for change, the contents cushioned it and process (support of senior management, IT and a good methodology) functioned as a vehicle to implement the initiative.
\end{abstract}

Keywords: Reengineering, strategic change, process management, contextual approach to change, case study

\section{INTRODUCTION}

Dawson, who is one of advocates of the processual approach to change reports that this approach is gaining popularity for understanding management and organizations. He notes, "in the case of organizational change, the process of transition is generally studied over time and within an historical and organizational context” [1]. The contextual theory is a multi-disciplinary approach and is concerned with a detailed examination of the process of change. It draws on the information provided by business historians, corporate strategists and organization theorists [2]. Key features of processual approach has been put forward by Pettigrew [3] Clark et al [4] and Dawson [5]: contextualist moved beyond a rational model of change in attempting to explain the political arenas in which decisions are made, histories deconstructed, and results rationalized. In short, the grouping of research under what has been termed as the contextualist approach includes those who seek to combine a fully historical perspective with emerging organizational dramas and those which are concerned with more processual work.

Since Business process re-engineering is considered a form of strategic change [6] it can be examined through a contextual framework. This study draws on Pettigrew et al's [7] processual approach to strategic change in order to examine a radical change initiative in a large organization since radical change has

Journal of Independent Studies and Research (JISR) Volume 5, Number2, July 2007
Received little attention in literature from a contextual perspective. Pettigrew and his colleagues [7] argue that this model is useful to implement new strategies (such as BPR) in order to improve organization's competitive performance. The paper provides exemplar to present and potential managers to design change programmes more effectively by taking benefits of context and its impacts on outcomes. It also increases the institutional knowledge of academic researchers since they are always keen to know about what is happening within organizations.

\section{COMPANY BACKGROUND AND RESEARCH METHODOLOGY}

British Aeronautical Company (BAC) is a large organization located in five geographical locations and is being managed by a team of ten directors and a managing director. It manufactures hi-tech and high unit value products for national and international customers. Training and post sale service is an essential factor of purchase agreement. Various versions of a single product are in operation, which are usually upgraded in order to keep the products up to date for the changing requirements of customer. Business Process Management (BPM) or BPR was launched in 1994 with a view to improve operational efficiency and competitiveness. Initially management envisioned that the programme would be completed within five years but it took longer than that. The initiative was a successful step to enhance internal efficiency and improve competitiveness.

A qualitative route was adopted to investigate the transformation. The case study approach was deemed appropriate because it offered to look into the change in detail without physical intervention. Interviews with the key players provided the insight necessary to unveil the process of change. The documents corroborated the views of participants and offered the basis for analysis within the processual framework. Informal interaction enhanced the fundamental data collection strategies. The researcher enabled to conduct seven interviews with process improvement team leaders and business process service managers (also known as internal consultants). The analysis is based on the transcription of the interviews together with documents, usually internal unpublished reports about the process and product of business process reengineering. 


\section{PHASES OF IMPLEMENTATION}

The implementation process has been divided according to the elements of the Pettigrew et al's framework and are inextricably interconnected in a sequential manner. For instance, the contents are based partially on the context and the process is linked with content. The are taken in turn.

\subsection{The context}

The context describes the conditions within which the change initiative had been launched such as the economic environment, the political conditions within the country or at the international level, the culture, organisational structure, cost behaviour, and so on. Context can be split up into the inner and outer sections.

The hierarchical structure, power-based relations, traditional culture and operational inefficiency were the key characteristics of BAC's inner context. They were not conducive for the implementation of a radical change initiative and the creation of a culture that could sustain it. Culture is closely associated with structure, and functional structure often produces bureaucratic elements in the culture whereby people are involved in 'building empires' rather than in sharing power. People may thus be unfamiliar with working in teams and managers had to function as a 'boss' rather as a coach. Some of the BAC managers were not IT-literate and tended to be against the dominance of technology in day-to-day activities. People also had unfavourable views about both BPR and consultants in general. They regarded BPR as a movement for redundancy and consultants as unproductive externals. Overall, therefore, BAC management had a limited view of BPR's scope or its possible success because there was a general lack of understanding of the new management philosophy.

Seddon [8] argues that traditional culture impedes effective change; he says "in traditional command and control cultures, managers think about their organizations as a collection of functions... In many cases BPR is treated as a project. The project team is to do the analysis and implement the required changes. However, if management thinking and behavior remains the same (attending to functional performance), the result is only a re-arrangement of the original pathology" BAC [9]. personnel also felt the negative impacts of hierarchical structure and functional influences stifled creativity and ultimately change Many other companies were facing similar problems during the period. Harvey [10] reported that the Baxi Partnership was implicitly experiencing problems in her organizational structure and was forced to re-organize herself into six strategic business units prior to embarking on BPR. The purpose was to change the culture by flattening the tall structure, encouraging empowerment, use of IT and improving operational ineffectiveness. It needed the removal of non-value added activities and streamlining business processes.

The outer context was demanding change because the competition was tough, competitors were changing competitive strategies, and demand was shrinking. There was strong downward pressure on customers' defense budgets and key customers were changing their procurement policies. BAC was not alone in confronting competition in the defense market since the collapse of the former Soviet Union pressurized the whole international defense industry. As a result, the demand started to shrink in the first place. Competitors changed the basis of competition from technology alone to consolidation and price. It also opened the doors for the customer from the defense industry of the former USSR. They have got more choice to select from the best of breed products; consequently they changed the procurement policies. Some of them re-directed their national budgets towards economic and social welfare programmes instead of defense.

These concerns were dealt in industry through restructuring and down sizing. Bishop and Williams [11] state the situation; the defense market is characterized by a close relationship amongst management, the military and the state. In the UK this stability was broken as a result of changes in the domestic and international defense environment in the 1980s. Many defense companies suffered. Some moved into civilian markets, others went overseas. These developments appear to have been associated with restructuring.

Restructuring was the viable alternative available to save the industry. However this was a very hard decision since BAC alone lost 20,000 jobs from 1990 to 1994 [12]. The company was not alone in the disaster; the other side of the Atlantic also suffered heavy loses. Bates and Kukalis [13] report that in the golden years of the 1980s, almost 12,000 Southern California firms were linked to the aerospace/defense market. Since 1989, the year when the Berlin Wall fell, Southern California lost 175,000 (44.7\%) of its high-tech jobs. Base closures will shrink the market by another estimated 33,000 jobs and the aerospace/defense industry expects to lose another 220,000 before 1995 .

\subsection{The content}

Content covers the components of the strategy which were implemented under the banner of radical change. They include prior competitive strategy, contribution of functions, objectives of change, sources of 
competitive strategy and evaluation and measurement. In addition, the content aimed at addressing the key concerns identified in the context.

Although the previous change initiatives were not as successful as envisioned they provided a basis on which the radical change was started. The presence of previous initiatives has been supported by SBAC [14], which notes that successful organisations who implement BPR were involved in previous initiatives such as TQM and JIT etc. Since BAC experienced TQM, which shares many characteristics with BPR e.g. business processes as the basis of improvement and focus on customers, this experience was useful for embarking on re-engineering. Several functional departments played a significant role in the implementation. The Marketing department was in the forefront because supplier relations and customer involvement/satisfaction were the corner stones of marketing strategy. The strategy was necessary to establish backward integration with suppliers and forward integration with customers. SBAC's [14] survey has indicated that "the biggest gains are being made by companies that include suppliers and customers in their Business Process Re-engineering programmes". It also provides the basis to establish inter firm relations (in BAC case with suppliers and partners) for economic advantage, learning implications and strategic appropriateness [15]. They argue that "individual organizations can no longer rely on their own resources to compete in today's world. Rather, they should look for strategic interactions allowing them effectively leverage internal resources by investing in some core competencies and contracting out other knowledge domains" (Ibid., p. 159). IT and Personnel were other enablers and key participant in the change. The directors of both departments were proponents of the idea of BPR partly since the concept of re-engineering was developed in the IT field and Personnel saw it as an opportunity for the development of the organisation. Researchers identified IT as a critical enabler for the success of BPR projects [16]. Personnel or human resource issues were also prominent in the literature. Researchers at Warwick argue "that failing to give priority to human factors at a time of radical change can break an existing social contract within an organisation” [17]. Ranganathan and Dhaliwal [18] identified lack of effective human resource strategy in the implementation of BPR projects in Singapore in the unsuccessful initiatives.

From these arguments it seems that the directors of IT and Personnel were on the right track to advocate bringing in the re-engineering programme. The change agents adopted a defensive attitude (e.g. 'Patch Work Quilt' as a change strategy) towards the radical change. The change agents were conservative because Patch Work Quilt was a less risky strategy, which could be tailored with available resources. The Journal of Independent Studies and Research (JISR) Volume 5, Number2, July 2007
'Clean Slate' strategy did not allow utilisation of existing resources. Secondly, since the company experienced a number of failed change attempts, a low risk initiative was a logical direction in order to avoid probability of failure.

Management consultants played a vital role in the change initiative. BAC borrowed the services of external consultants in order to share knowledge and experience with them. It worked well; BAC managers learned the bits and bolts of BPR within two years and then external consultants were withdrawn. Researchers support the application of consultants in the reengineering initiative; Carter and Crowther [19] regard them as "fuelling the process" of change. On the other hand there are some reservations about the use of consultants in generic change programmes but the researcher did not find any reference, which opposes the use of them in BPR projects. SBAC [14] reported a firm who did not use consultants on the ground that the firm wanted to promote its own people. But the firm did not object the role of consultants in BPR.

The political objective of the change was to enhance control on the employee, customer and suppliers. For instance, the QA and Ops projects strengthened control of employee activities and put more control on them by specifying standards and integrating manufacturing activities. IPL/IPC, S\&R and ISFI facilitated customer by specified lists of parts and equipment, providing effective supply support and prevention and correction of faults of in-service aircraft. This gave increased control on the products/equipment supplied to customer and purchases made from the supplier. The responsibility of quality and quantity has been transferred to suppliers in that all suppliers have access to BAC database; re-order level is monitored by them rather than at the BAC purchasing department. In addition, the whole lot is returned to supplier even if a single item did not meet the quality standard.

\subsection{The process}

According to Pettigrew [7] and his colleagues, the process contains five key components: triggers for change, management process and actions, implementation process, availability of technology, and time frames for change. They are taken in turn now in the following paragraphs.

Contextual factors were the key triggers for change. Cost control and affordability stem from them since contextual elements forced management to reduce cost and make the product affordable to customers. Context has already been discussed above, however, most of the contextual elements emerged from legacy of management practices such as hierarchical 
structure and political changes i.e. collapse of the former Soviet Union. They can be grouped into three headings: competitive environment, pursuing strategic benefits, and process issues. Similar reasons have been identified in a recent survey; Kallio et al [20] found that $78 \%$ of the respondents started BPR in response to changes in the competitive environment, $59 \%$ in active pursuit of strategic benefits and $47 \%$ for problems recognised in business processes. BAC's triggers were no different from other companies in the industry since the cause of all their problems was the same i.e. end of the Cold War.

Five types of change agents were used for implementation. Senior managers were an essential input in order to involve them and gain their commitment. The Product Board of various aircraft such as EU2 offered coordination between product and PITs. The internal and external consultants were necessary for training the employees and the PIT members about BPR tools and techniques. The external consultants brought in the radical change methodology that provided a starting point and a structure for the change initiative. The Process Improvement Team functioned as an operational management team during the whole process of change. This shows that the change agents were an integrated rich picture of the management structure used for BPR. It seems a strong coalition of internal and external managerial experience and resources. Research in other organisation throws light on the variety of change agents involved in reengineering. For example, Withman [21] identified that "business managers, executives, administrative/staff personnel, IT personnel, and consultants are actually involved in re-engineering projects”. Functional executive were also key participants [18]. The involvement of senior managers was a dominant factor in the success of BPR. Dennis et al [22] state that "The key difference between the successful and the unsuccessful cases was when and how senior management was involved".

The decision pattern was democratic and negotiated. For instance, participants in the design workshops negotiated for the future vision of a process. Recommendations were forwarded either by consensus or on the basis of majority. The negotiated style of management is commensurate with the sort of organisation BAC is, since command and control culture is difficult to work in such an organisation. Force Field analysis and Delta Analysis were used as dominant theoretical change models. The Delta analysis assumes filling a gap between the current situation and the future desired situation. Force Field analysis is also based on similar parameters where driving forces and restraining forces are identified. The restraining forces are removed to achieve a state of change. As BAC upgraded most of the business processes to the standard of best practice companies, Journal of Independent Studies and Research (JISR) Volume 5, Number2, July 2007 this implies that a gap has been closed between BAC culture and the best practice culture. It seems a conservative and less risky strategy, which is an appropriate approach within the company context and international circumstances.

Technology played an enabling role in the programme. Redesign of many processes was possible due to deployment of appropriate technology enablers. For example, EDI was applied in supply chain related processes such as S\&R, Procurement and IPC/IPL processes. Without availability of technology the redesign of these processes would not have been possible. Wu [23] views technology as an enabler, he says, "IT is a major facilitator of BPR and it must be considered in the process of implementation. Finally, the time period for process redesign was one year. Six months were allocated for implementation, evaluation and envision took three months each. The evaluation and envision were complying with the time frame but implementation took more than the estimated time period. Hammer and Champy [24] suggest a similar time frame for a radical change project.

\section{CONCLUSION}

Examining Business Process Management (BPM) using processual framework is important form two dimensions. Some characteristics are common in both change approaches: both are strategic in nature. A strategic approach is initiated and supported by senior management which is a key success factor in radical change programmes. Harvey [11] identified that patronage of top management was necessary for the success of process-based change. Pettigrew and his colleagues [7] and Dawson [5] put forward the same argument for processual change (PC). The PC breaks up the process of change into three components, which are logical and provide a structure to the change agents.

Some characteristics between them are however, different. The PC implements changes in functional perspective whereas BPM rely on business processes to implement new procedures and methods. It is primarily due to absence of process based change techniques in the developmental period of PC. The PC flourished in the 1980s and BPM emerged on the management horizon in the early 1990s. Secondly, BPM assigns technology a key role to play in the transformation while PC recognizes only the availability of technology to support change. Thirdly, BPM seeks radical solutions to modern business issues whereas PC is comfortable to any magnitude of change.

It suggests that there are some deficiencies in the PC despite a number of merits. On the other hand there 
are some beneficial merits of BPM: process orientation, role of IT and the high magnitude of change. So it would be useful to combine them to analyze a change initiative in order to take advantage of both techniques which have something in common i.e. strategic orientation. Also the combination provides increased coordination between business processes and functional departments without making the structure too tall.

The learning from the case study can be used in other organizations in two ways: the companies with similar drivers for change can use them straightaway as BAC has done and the companies with different drivers for change can use them as a starting point. They can modify their strategy later on according to their needs and resources available. Some factors are, however, common to any process based change. For instance, initiation and commitment of change must be at top level of management, IT should provide a lever and business processes must be the centre of transformation.

\section{REFERENCES}

[1] Dawson, P. In at the deep end: Conducting processual research on organizational change, Scandinavian Journal of Management, 13 (4): 389405, 1997.

[2] Whipp, et al. editors. The Management of Strategic Change. Basil Blackwell: Oxford, 1987.

[3] Pettigrew, A. M. editor. Organizational Strategy and Change, Jossey-Bass: San Francisco, 1985.

[4] Clark, et al. The Process of Technology Change: New Technology and Social Choice in the Workplace, Cambridge University Press, Cambridge, 1988.

[5] Dawson, P. Organizational Change: A Processual Approach. Paul Chapman Publishing Ltd, London, 1994.

[6] Kettinger, William J., Teng, James T. C \& Guha, Subashish. Business Process Change: A Study of Methodologies, Techniques, and Tools, Management Information Systems Quarterly, 21 (1): 55-80, 1997.

[7] Pettigrew, A.M., Whipp, R. \& Rosenfeld, R. Competitiveness and the management of strategic change. In Arthur Francis \& P. K. M. Tharakan, The competitiveness of European industry London: Routledge, 1989.

[8] Seddon, J. Business Process Re-engineering and culture

change, http://www.leanservice.co.uk/members/library/bus_pr oc_reeng.asp., 2001.

[9] BAC, Procurement Evaluation Report, 1993c.

[10] Harvey, J. Re-engineering: the critical success factor. Management Today in association with Business Intelligence Limited, 1994.

[11] Bishop, P. \& Williams, T. Restructuring the UK Defense Industry: Market Pressures and Management Initiatives, Long Range Planning, 30 (1): 21-28, 1997.

[12] BAC, Annual Business Plans,1994.

[13] Bates, D. L. \& Kukalis, S. The endgame in aerospace: A disaster waiting to happen?, Long Range Planning, 31 (4): 615-22, 1998.

[14] SBAC, Report on Business Process Reengineering within the Aerospace Industry. Society of British Aerospace Companies, 1995.

[15] Sobrero, M. \& Roberts, E. B. Strategic management of supplier-manufacturer relations in new product development, Research Policy, 31 (11): 159-182, 2002.

[16] Teng et al, J. T. C. An exploratory study of the influence of the IS function and organizational context on business process reengineering project initiatives, Omega, 26 (6): 679-698, 1998.

[17] Peltu, M., Clegg, C., and Sell, R. Business Process Re-engineering: The Human Issues, Proceeding of Forum 4, ESRC Business Processes Resource Centre, University of Warwick: Warwick, 1996.

[18] Ranganathan, C. \& Dhaliwal, J. S. A survey of business process reengineering practices in Singapore, Information \& Management, 39 (2): 125-134, 2001.

[19] Carter, C. \& Crowther, D. Organizational consumerism: the appropriation of packaged managerial knowledge, Management Decision, 38 (9): 626-637, 2000.

[20] Kallio et. al., J. Drivers and tracers of business process changes, The Journal of Strategic Information Systems, 8 (2):125-142, 1999.

[21] Whitman, Michael E. IT divergence in reengineering support: Performance expectations vs. perceptions, Information \& Management, 30 (5): 239250, 1996. 
[22] Dennis, et. el. Breaking the rules: success and failure in groupware-supported business process reengineering', Decision Support Systems, 36 (1): 3147, 2003.

[23] Wu, Ing-Long A model for implementing BPR based on strategic perspectives: an empirical study, Information \& Management. 39 (44): 313-324, 2002.

[24] Hammer, M., \& Champy, J. Re-engineering The Corporation. Nicholas Brealey Publishing: London, 1993. 